\title{
PENGARUH DESAIN CAFE UNTUK MENARIK PARA PENGUNJUNG TERHADAP PENINGKATAN PENGUNJUNG STUDY KASUS PADA CAFE RAHAYU \& RESTO DI SEI RAMPAH KABUPATEN SERDANG BEDAGAI
}

\author{
${ }^{1}$ Tomy Agustiawan, ${ }^{2}$ Muhammad Rahmat \\ ${ }^{1,2}$ Universitas Muslim Nusantara Al-Washliyah Medan \\ Itomyagustiawan52@gmail.com, ${ }^{2}$ Muhammad.rahmat@gmail.com
}

\begin{abstract}
This study aims to determine the effect of cafe design on increasing visitors to Cafe Rahayu \& Resto in Sei Rampah, Serdang Bedagai Regency. The sampling technique used is the random sampling method, which is taking samples from the population at random without regard to the existing strata in the population of 84 people. Methods of data collection using a questionnaire. In the partial hypothesis test ( $t$ test) the cafe design variable has a positive and significant effect on increasing visitors with a $t$ count $>t$ table $(12.766>1.989)$ and a significant value of $0.000<$ 0.05 . The results of the determination test obtained an $R$ Square value of 0.665 , meaning that the variable increase in visitors can be explained by $66.5 \%$ by the cafe design variable, while the remaining $33.5 \%$ is explained by other variables not included in this study.
\end{abstract}

Keywords: Cafe Design and Increasing Visitors Peningkatan

ABSTRAK : Penelitian ini bertujuan untuk mengetahui pengaruh desain cafe terhadap peningkatan pengunjung pada Cafe Rahayu \& Resto di Sei Rampah Kabupaten Serdang Bedagai. Teknik pengambilan sampel menggunakan metode random sampling, yaitu pengambilan sanggota sampel dari populasi dilakukan secara acak tanpa memperhatikan strata yang ada dalam populasi berjumlah 84 orang. Metode pengumpulan data menggunakan kuesioner. Pada uji hipotesis parsial (Uji t) variabel desain cafe berpengaruh positif dan signifikan terhadap peningkatan pengunjung dengan nilai $t$ hitung $>t$ tabel $(12,766>1,989)$ dan nilai signifikan 0,000 < 0,05. Hasil uji determinasi diperoleh nilai $R$ Square sebesar 0,665, artinya variabel peningkatan pengunjung dapat dijelaskan sebesar 66,5\% oleh variabel desain cafe, sementara sisanya 33,5\% dijelaskan oleh variabel lain yang tidak dimasukkan dalam penelitian ini.

Kata Kunci : Disain café dan peningkatan pengunjung.

\section{Pendahuluan}

Seiring berjalannya waktu, bisnis cafe pada era modern ini merupakan suatu bisnis yang menjanjikan. Bukan hanya sebagai tempat makan, banyak masyarakat yang menjadikan cafe sebagai tempat untuk berkumpul dan bahkan dijadikan sebagai tempat meeting kerja. Hal ini ditinjau dari gaya hidup masyarakat masa kini yang cenderung senang bertatap muka, bersantai dan berbincang. Telah menjadi suatu kebiasaan bagi masyarakat untuk bersosialisasi, dan mayarakat membutuhkan suatu sarana dalam mewujudkan keinginan mereka. Oleh karena itu, dengan adanya cafe dimaksudkan untuk merealisasikan kebutuhan masyarakat yaitu sarana berkumpul. Banyaknya cafe yang bermunculan mengakibatkan para pemilik berpikir lebih kreatif untuk menciptakan desain yang berbeda dari cafe cafe yang sudah ada. Hal tersebut diperlukan untuk menarik perhatian para pengunjung. Pada umumnya, para pemilik cafe terlebih dahulu mensurvei apa yang menjadi tren di pasaran masyarakat atau dari kebiasaan-kebiasaan masyarakat. Masyarakat pada dasarnya sangat suka sesuatu hal yang baru serta berbeda dari yang sudah ada sebelumnya.

Untuk meningkatkan jumlah pengunjung cafe, para pelaku usaha harus memiliki ide-ide kreatif agar dapat menarik perhatian pengunjung, mulai dari menu yang ditawarkan atau desain cafe yang unik. Mengingat banyaknya pesaing yang bermunculan sehingga pimpinan cafe harus mampu dalam menarik para pengunjung untuk datang ke cafenya. Hal ini perlu dilakukan agar dapat terus bertahan 
dan menyeimbangkan atau bahkan dapat melebihi para pesaing. Dengan memenuhi keinginan pengunjung setiap harinya melalui ide-ide kreatif, maka akan menanamkan rasa penasaran kepada pengunjung untuk terus datang di cafe sehingga usaha yang dijalankan dapat terus bertahan. Salah satu ide kreatif yang dapat berpengaruh terhadap peningkatan pengunjung yaitu desain café yang menarik.

Desain cafe yang kreatif akan lebih bisa menarik para pengunjung. Para pengunjung pada umumnya lebih tertarik pada suasana baru dengan desain menarik dan berbeda dari yang sudah ada sebelumnya. Apabila café ditata secara apik, menggunakan tema tertentu akan membuat nyaman pengunjung. Sebab yang berkunjung ke cafe bukan hanya untuk mengenyangkan perut dengan sekedar makan dan minum, melainkan untuk bersantai dan menghabiskan waktu luang bersama keluarga, sahabat maupun kerabat kerja. Oleh sebab itu, pemilik cafe harus bisa menawarkan desain menarik bagi para pengunjung, baik desain kesederhanaan alamiah maupun kemewahan yang wajib ditawarkan.

Berdasarkan fenomena-fenomena tersebut diatas penulis akan melakukan penelitian dengan judul: "Pengaruh Desain Cafe Untuk Menarik Para Pengunjung Terhadap Peningkatan Pengunjung Study Kasus Pada Cafe Rahayu \& Resto di Sei Rampah Kabupaten Serdang Bedagai”.

\subsection{Rumusan Masalah}

Menurut Sugiyono (2016:35) rumusan masalah merupakan suatu pertanyaan yang akan dicarikan jawabannya melalui pengumpulan data". Maka berdasarkan batasan masalah yang telah ditentukan diatas dapat dirumuskan permasalahan yaitu:

1) Apakah desain cafe berpengaruh terhadap peningkatan pengunjung pada Cafe Rahayu \& Resto di Sei Rampah Kabupaten Serdang Bedagai?

2) Seberapa besar Pengaruh Desain Cafe terhadap peningkatan pengunjung pada Cafe Rahayu \& Resto di Sei Rampah Kabupaten Serdang Bedagai?

\subsection{Batasan Maslah}

Menurut Arikunto (2016:22), batasan masalah merupakan bagian dari kebutuhan seseorang untuk dipecahkan". Maksudnya ialah fokus pada ruang lingkup yang diteliti sampai menimbulkan jawaban dalam diri seseorang yang mencari permasalahan. Dalam peneitian ini penulis membatasi permasalahan pada Pengaruh Desain Cafe untuk menarik para pengunjung terhadap peningkatan pengunjung study kasus pada Cafe Rahayu \& Resto di Sei Rampah Kabupaten Serdang Bedagai.

\subsection{Tujuan Penelitian}

Menurut Arikunto (2013:97) mengatakan, tujuan penelitian adalah rumusan kalimat yang menunjukan adanya sesuatu hal yang diperoleh setelah penelitian selesai. Penelitian dilakukan tentunya karena ada hal yang akan dituju. Berdasarkan rumusan masalah diatas maka tujuan dan penelitian ini adalah:

1) Untuk mengetahui pengaruh Desain Cafe terhadap peningkatan pengunjung pada Cafe Rahayu \& Resto di Sei Rampah Kabupaten Serdang Bedagai.

2) Untuk mengetahui seberapa besar pengaruh Desain Cafe terhadap peningkatan pengunjung pada Cafe Rahayu \& Resto di Sei Rampah Kabupaten Serdang Bedagai.

\section{METODE PENELITIAN \\ 2.1 Populasi}

Menurut Sugiyono (2016:148) populasi adalah wilayah generalisasi yang terdiri atas objek yang mempunyai kualitas dan karakteristik tertentu yang ditetapkan oleh penelitian untuk dipelajari dan kemudian ditarik kesimpulannya. Dalam penelitian ini yang menjadi populasi adalah pengunjung Cafe Rahayu \& Resto, dengan rata-rata perbulan yaitu 1.687 orang.

\subsection{Sampel}

Menurut pendapat Sugiyono (2016:149) sampel adalah bagian dan jumlah dan karakteristik yang dimiliki oleh populasi tersebut. Jika jumlah subjeknya besar, dapat diambil antara 5\% - 15\% atau 20\% - 25\% atau lebih. Tetapi apabila subjeknya kurang dari 100, lebih baik diambil semua sehingga penelitiannya merupakan penelitian populasi. Teknik penarikan sampel penelitian ini menggunakan teknik random sampling yaitu teknik pengambilan sampel dari anggota populasi yang dilakukan secara acak tanpa memperhatikan strata yang ada dalam populasi itu. Penelitian ini mengambil sampel secara keseluruhan dari 
total populasi yaitu sebanyak $5 \%$ dari total populasi yaitu 84 orang.

\subsection{Uji Normalitas}

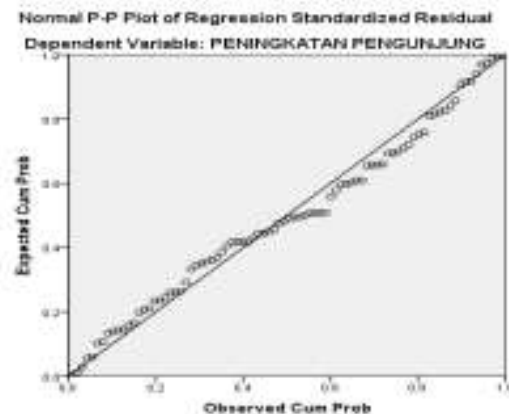

Gambar 1. Normal P-P Plot Histogram

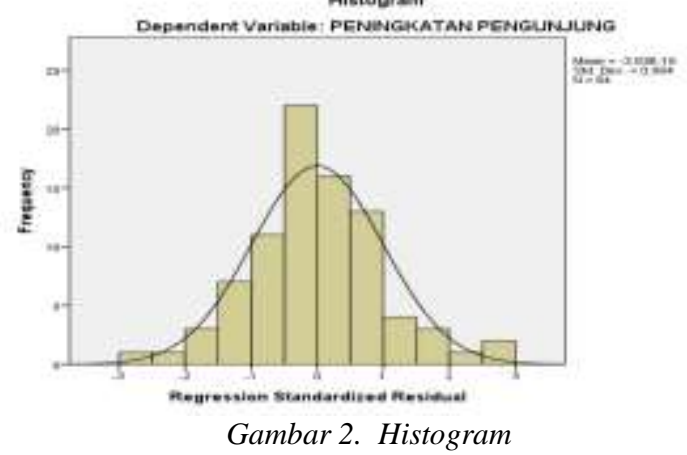

Gambar 1, normal p-p plot menunjukkan bahwa data menyebar di sekitar garis diagonal dan mengikuti arah garis diagonal. Gambar 2 histogram memperlihatkan bahwa distribusi data penelitian yang dilakukan membentuk lonceng (bell shaped), tidak condong ke kiri atau tidak condong ke kanan sehingga grafik histogram tersebut dinyatakan normal.

Untuk melihat apakah data terdistribusi normal atau tidak peneliti menggunakan metode One Sample Kolmogorov-Smirnov dengan kriteria nilai signifikan > 0,05 maka terdistribusi secara normal. Berikut adalah hasil ujinya :

Tabel 1. Hasil Uji Normalitas

One-Sample Kolmogorov-Smirnov Test

\begin{tabular}{|ll|r|r|}
\hline & & DESAIN CAFE & $\begin{array}{r}\text { PENINGKATAN } \\
\text { PENGUNJUNG }\end{array}$ \\
& & 84 & 84 \\
$\mathrm{~N}$ & Mean & 38.11 & 39.26 \\
Normal Parameters & & 5.591 \\
& Std. Deviation & 7.865 & .124 \\
Most Extreme Differences & Absolute & .132 & .069 \\
& Positive & .072 & -.124 \\
Kolmogorov-Smirnov Z & Negative & -.132 & 1.136 \\
Asymp. Sig. (2-tailed) & & 1.211 & .151 \\
\hline a. Test distribution is Normal. & & .107 & \\
b. Calculated from data. & & &
\end{tabular}

Sumber : Hasil Penelitian, 2021

Berdasarkan tabel hasil One Sample Kolmogorov-Smirnov tersebut diperoleh nilai signifikansi variabel desain cafe (X) sebesar 0,107 dan variabel peningkatan pengunjung $(\mathrm{Y})$ sebesar 0,151 lebih besar dari 0,05 sehingga dapat disimpulkan bahwa data yang diuji terdistribusi normal.

\section{Hasil dan Pembahasan}

\subsection{Analisis Regresi Linear Sederhana}

Analisis regresi linear sederhana dalam penelitian ini bertujuan untuk mengetahui pengaruh antara variabel Desain Cafe (X) terhadap variabel Peningkatan Pengunjung (Y). Hasil analisis regresi linear sederhana dapat dilihat pada tabel dibawah ini : 
Tabel 2. Hasil Uji Regresi Linear Sederhana

Coefficients $^{\mathrm{a}}$

\begin{tabular}{|c|c|c|c|c|c|c|}
\hline \multirow[t]{2}{*}{ Model } & & \multicolumn{2}{|c|}{$\begin{array}{l}\text { Unstandardized } \\
\text { Coefficients }\end{array}$} & \multirow{2}{*}{$\begin{array}{c}\text { Standardized } \\
\text { Coefficients } \\
\text { Beta } \\
\end{array}$} & \multirow[t]{2}{*}{$\mathrm{t}$} & \multirow[t]{2}{*}{ Sig. } \\
\hline & & B & Std. Error & & & \\
\hline \multirow[b]{2}{*}{1} & (Constant) & 17.168 & 1.767 & & 9.717 & .000 \\
\hline & $\begin{array}{l}\text { DESAIN } \\
\text { CAFE }\end{array}$ & .580 & .045 & .816 & 12.766 & .000 \\
\hline
\end{tabular}

Sumber : Hasil Penelitian, 2021

Dari tabel tersebut diketahui persamaan regresi linear sederhana antara variabel independen dan variabel dependen sebagai berikut :

$$
\mathrm{Y}=\mathbf{1 7 , 1 6 8}+\mathbf{0 , 5 8 0 X}+\mathrm{e}
$$

Dari persamaan regresi tersebut dapat disimpulkan bahwa :

1) Konstanta (a) $=17,168$ artinya jika Desain

Cafe bernilai 0 maka Peningkatan Pengunjung pada Cafe Rahayu \& Resto di Sei Rampah Kabupaten Serdang Bedagai adalah sebesar 17,168.

2) Koefisien regresi variabel Desain Cafe $=$ 0,580 artinya jika variabel Desain Cafe meningkat sebesar 1 satuan maka variabel

Peningkatan Pengunjung akan meningkat 0,580 .

\subsection{Pengujian Hipotesis}

\subsubsection{Uji Parsial (Uji t)}

Nilai koefisien regresi dalam persamaan regresi merupakan hasil perhitungan berdasarkan sampel yang dipilih. Pengujian ini dilakukan untuk mengetahui pengaruh variabel bebas terhadap variabel terikat secara parsial. Pengujian melalui uji $t$ adalah dengan membandingkan $t$ hitung. Kriteria pengambilan keputusan adalah : Tingkat kesalahan $(\alpha)=5 \%$ dan derajat kebebasan $(\mathrm{df})=\mathrm{n}$ (jumlah sampel) $-\mathrm{k}$ (jumlah variabel yang digunakan $)=84-2=$ $82, \mathrm{t}$ tabel $=1,989$

Tabel 3. Hasil Uji Parsial (Uji t) Coefficients $^{\mathrm{a}}$

\begin{tabular}{|c|c|c|c|c|c|c|}
\hline \multirow[t]{2}{*}{ Mode } & & \multicolumn{2}{|c|}{$\begin{array}{l}\text { Unstandardized } \\
\text { Coefficients }\end{array}$} & \multirow{2}{*}{$\begin{array}{c}\begin{array}{c}\text { Standardized } \\
\text { Coefficients }\end{array} \\
\text { Beta }\end{array}$} & \multirow[t]{2}{*}{$\mathrm{t}$} & \multirow[t]{2}{*}{ Sig. } \\
\hline & & B & Std. Error & & & \\
\hline \multirow[b]{2}{*}{1} & (Constant) & 17.168 & 1.767 & & 9.717 & .000 \\
\hline & $\begin{array}{l}\text { DESAIN } \\
\text { CAFÉ }\end{array}$ & .580 & .045 & .816 & 12.766 & .000 \\
\hline
\end{tabular}

Sumber : Hasil Penelitian, 2021

Berdasarkan tabel di atas, dapat dilihat pengaruh variabel secara parsial sebagai berikut :

a. Berdasarkan analisis regresi diperoleh nilai $t$ hitung sebesar 12,766 > t tabel 1,989 ini berarti variabel Desain Cafe berpengaruh positif terhadap Peningkatan Pengunjung. Nilai signifikan $0,000<0,05$ ini berarti variabel Desain Cafe signifikan terhadap Peningkatan Pengunjung.

\subsubsection{Uji Koefisien Determinasi $\left(\mathbf{R}^{2}\right)$}

Pengujian koefisien determinasi $\left(\mathrm{R}^{2}\right)$ digunakan untuk melihat seberapa besar kontribusi variabel independen terhadap variabel dependen". Semakin besar nilai koefisiensi determinasi maka semakin baik kemampuan variabel $(\mathrm{X})$ menerangkan variabel (Y). Koefisien determinasi ditentukan dengan nilai $R$ Square sebagaimana dapat dilihat pada tabel berikut ini : 
Tabel 4. Koefisien Determinasi $\left(\mathrm{R}^{2}\right)$

Model Summary ${ }^{\mathrm{b}}$

\begin{tabular}{|l|r|r|r|r|}
\hline Model & $\mathrm{R}$ & $\mathrm{R}$ Square & $\begin{array}{c}\text { Adjusted R } \\
\text { Square }\end{array}$ & $\begin{array}{c}\text { Std. Error of } \\
\text { the Estimate }\end{array}$ \\
\hline 1 & $.816^{\mathrm{a}}$ & .665 & .661 & 3.254 \\
\hline
\end{tabular}

a. Predictors: (Constant), DESAIN CAFÉ

b. Dependent Variable: PENINGKATAN PENGUNJUNG

Sumber : Hasil Penelitian, 2021

Berdasarkan tabel tersebut, dapat diambil kesimpulan bahwa tingkat pengaruh dari Desain Cafe terhadap Peningkatan Pengunjung adalah 0,665. Dari hasil perhitungan koefisien determinasi, dapat dijelaskan bahwa Desain Cafe memiliki pengaruh sebesar $66,5 \%$ terhadap Peningkatan Pengunjung, sementara sisanya sebesar $33,5 \%$ dipengaruhi oleh variabel lain yang berada diluar penelitian

\section{Hasil Analisa}

\subsection{Pengaruh Desain Cafe Terhadap Peningkatan Pengunjung}

Konsep desain merupakan sebuah perencanaan tentang layout dan desain ruangan dengan menata dan merancang ruang-ruang interior bangunan sehingga memungkinkan pemakai aktivitas ruangan dapat beraktivitas dalam ruangan tersebut secara nyaman dan efektif. Berman dan Evan (2014:545) terdapat elemen yang menjadi indikator konsep desain yang terdiri dari Exterior, General Interior, Store Layout dan Interior Display. Menurut hasil wawancara dengan beberapa pengunjung diperoleh informasi bahwa desain Rahayu Cafe \& Resto terlalu monoton dimana penataan tempat, penyusunan kursi dan meja serta penerangan café yang tidak up to date sehingga suasana cafe terlihat cukup membosankan

Hasil penelitian ini menyatakan bahwa terdapat pengaruh Desain Cafe terhadap Peningkatan Pengunjung pada Cafe Rahayu \& Resto di Sei Rampah Kabupaten Serdang Bedagai. Variabel Desain Cafe memiliki t hitung > t tabel $(12,766>1,989)$ dan nilai signifikan $0,000>0,05$. Sesuai dengan uraian tersebut dapat disimpulkan bahwa Desain Cafe berpengaruh positif dan signifikan terhadap Peningkatan Pengunjung sehingga hipotesis diterima. Hasil penelitian ini sejalan dengan hasil penelitian yang dilakukan oleh Juliana, dkk (2020) yang menyatakan bahwa Desain Cafe berpengaruh positif dan signifikan terhadap Peningkatan Pengunjung.
Hasil perhitungan koefisien determinasi, dapat dijelaskan bahwa Desain Cafe memiliki pengaruh sebesar $66,5 \%$ terhadap Peningkatan Pengunjung, sementara sisanya sebesar 33,5\% dipengaruhi oleh faktor yang lain yang berada diluar penelitian ini.

\section{Kesimpulan}

Berdasarkan hasil penelitian dan pembahasan dari penelitian yang telah dilakukan mengenai Pengaruh Desain Cafe Untuk Menarik Para Pengunjung Terhadap Peningkatan Pengunjung Study Kasus Pada Cafe Rahayu \& Resto Di Sei Rampah Kabupaten Serdang Bedagai, maka dapat ditarik kesimpulan sebagai berikut :

1) Desain Cafe berpengaruh positif dan signifikan terhadap Peningkatan Pengunjung Pada Cafe Rahayu \& Resto Di Sei Rampah Kabupaten Serdang Bedagai dengan nilai $\mathrm{t}$ hitung $>\mathrm{t}$ tabel $(12,766>1,989)$ dan nilai signifikan $0,000<0,05$.

2) Hasil perhitungan koefisien determinasi, dapat dijelaskan bahwa Desain Cafe memiliki pengaruh sebesar $66,5 \%$ terhadap Peningkatan Pengunjung sementara sisanya sebesar 33,5\% dipengaruhi oleh faktor yang lain yang berada diluar penelitian ini.

\section{DAFTAR PUSTAKA}

Ahmed, K. M. (2020) 'Effect of Design Elements for Social Media Ads on Consumer's Purchasing Decision', Global Media Journal, 18(34), pp. 1-12.

Arikunto, S. (2016). Prosedur Penelitian Suatu Pendekatan Praktik. Jakarta: Rineka Cipta.

Berman, B., and Evans, J. R. (2014). "Retail Management" dialihbahasakan oleh Lina Salim, 12 th. Edition. Jakarta: Pearson.

Binggeli. (2012). Interior Design Illustrated. New Jersey: Wiley.

Gera, L. and Kusowidagdo, A. (2020) 'Pengaruh Atmosfer Pada Desain Interior Café Kelana', Jurnal Seminar Nasional Envisi. 2(1), pp.187-198. 
Herman, Malau. (2017). Manajemen Pemasaran. Alfabeta, Bandung.

Juliana., Agatha, N., and Felicia. (2020) 'Pengaruh Desain Interior Terhadap Minat Pengunjung Di Restoran The Garden Pantai Indah Kapuk', Cakrawala, 20(1), pp. 28-34.

Kotler, P., and Keller, K. L. (2016). Manajemen Pemasaran edisi 12 Jilid $1 \& 2$. Jakarta: PT. Indeks.

Kuncoro, M. (2015). Masalah, Kebijakan, dan Politik Ekonomika Pembangunan. Jakarta: Erlangga.

Martono, Nanang. 2015. Metode Penelitian Kuantitatif. Jakarta. Rajawali Pers.

Panjaitan, S. W. (2016) 'Pengaruh Desain Interior Perpustakaan Terhadap Kenyamanan Pengguna di Perpustakaan Universitas Potensi Utama', Jurnal Proporsi, 1(2), pp. 142-152.

Priansa, D. J. (2017). Komunikasi Pemasaran Terpadu (Pada Era Media Sosial). Bandung: Pustaka Setia.

Rahman, M. F. N. and Jumino (2020) 'Peran Desain Interior Dalam Menunjang Kenyamanan Pengguna di Perpustakaan Badan Pusat Statistik Provinsi Jawa Tengah', Anuva, 4(1), pp. 81-98.

Rasyid, M. N., Nuhung, M., Abadulla, I., and Hamzah, A. I. P. (2020) 'Pengaruh Relationship Marketing Terhadap Peningkatan Pengunjung Pada Hotel Harper Perintis Makassar', Jurnal Ilmu Manajemen Profitability, 4(2), pp. 80-101.

Sangadji, E.M., dan Sopiah. (2013). Prilaku Konsumen: Pendekatan Praktis. Disertai:Himpunan Jurnal Penelitian. Yogyakarta: Penerbit Andi.

Septiawan, M. R. (2014). 'Pengaruh Desain Interior Perpustakaan ITS Surabaya Terhadap Kenyamanan Pengguna', Jurnal ITS Surabaya, pp. 1-13.

Serhan, M. and Serhan, C. (2019) 'The Impact of Food Service Attributes on Customer Satisfaction in a Rural University Campus Environment', International Journal of Food Science, 2(1), pp. 1-13.

Sugianto, J. and Sugiono (2013) 'Analisis Pengaruh Service Quality, Food Quality, dan Price terhadap Kepuasan Pelanggan Restoran Yung Ho Surabaya', Jurnal Manajemen Pemasaran Petra, 2(1), pp. 110.

Sugiyono. (2016). Metode Penelitian Kuantitatif Kualitatif $R \& B$. Bandung: Aflabeta.
Susanto, V. Amir, M. A. M., Haqqi, M. A., Ekomadyo, A. S., \& Riska, A. S (2020) 'Pengaruh Gaya Hidup Milenial Terhadap Desain Arsitektur Kafe, Jurnal Arsitektur, Bangunan \& Lingkungan, 9 (2) pp. 69-80. 